\title{
A RANDOMIZED TRIAL OF THREE PSYCHOSOCIAL TREATMENTS FOR THE SYMPTOMS OF RHEUMATOID ARTHRITIS
}

\author{
Arthur J. Barsky, MD*, David K. Ahern, Ph.D. , E. John Orav, Ph.D.†, Yvonne Nestoriuc, \\ Ph.D. ${ }^{a}$, Matthew H. Liang, M.D., M.P.H.§, Ilana T. Berman, Ph.D., M.A., Joshua R. \\ Kingsbury, M.S., Jennifer T. Sy, M.S., and Kathryn G. Wilk, CPNP, M.S., NP \\ "Department of Psychiatry, Brigham and Women's Hospital and Harvard Medical School \\ †Division of General Internal Medicine, Department of Medicine, Brigham and Women's Hospital \\ and Harvard Medical School \\ $\S$ Division of Rheumatology, Immunology and Allergy, Department of Medicine, Brigham and \\ Women's Hospital and Harvard Medical School \\ aDepartment of Clinical Psychology and Psychotherapy, Philipps University of Marburg
}

\begin{abstract}
Objective-To assess and compare the benefits of three psychosocial treatments for rheumatoid arthritis.

Methods-Rheumatoid arthritis (RA) patients were randomized to cognitive-behavior therapy (CBT), relaxation response training (RR), or arthritis education (AE). All treatment was conducted in groups. Follow-up occurred immediately after treatment and 6 and 12 months later. Pain, other RA symptoms, role impairment, and psychological distress were assessed with standardized selfreport questionnaires. Arthritis severity and activity were assessed with a joint examination, erythrocyte sedimentation rate, grip strength, and walking time. An intent-to-treat analytic strategy was employed. Linear regression was used to establish treatment effect on pain and other RA symptoms, while adjusting for sociodemographic and clinical variables.
\end{abstract}

Results-168 patients were randomized. Pain improved significantly at 12 months in the RR and AE groups and showed a non-significant positive trend with CBT. Other RA symptoms improved significantly with CBT and AE, and showed a non-significant trend with RR. There were no significant differences in the outcomes across the 3 treatment groups. When the results for all 3 groups were aggregated, significant benefits were found for pain, other RA symptoms, self-care activities and social activities. Effect sizes ranged between 0.26 and 0.35 .

Conclusions-These three psychosocial treatments were beneficial, with treatment effect sizes in the small to moderate range. The effects appeared immediately after treatment and were generally sustained at long-term follow-up. These benefits were achieved over and above those

(C) 2010 Elsevier Inc. All rights reserved.

Corresponding Author: Arthur J. Barsky, M.D., Department of Psychiatry, Brigham and Women's Hospital, 75 Francis Street, Boston, MA 02115, Tel: 617-732-5236, Fax: 617-278-6907, abarsky@partners.org.

Publisher's Disclaimer: This is a PDF file of an unedited manuscript that has been accepted for publication. As a service to our customers we are providing this early version of the manuscript. The manuscript will undergo copyediting, typesetting, and review of the resulting proof before it is published in its final citable form. Please note that during the production process errors may be discovered which could affect the content, and all legal disclaimers that apply to the journal pertain.

This study has been registered with ClinicalTrials.gov and received the identifier NCT00056667. 
resulting from medical management. These treatments constitute an effective augmentation to standard medical therapy for rheumatoid arthritis patients.

\section{INTRODUCTION}

Despite major advances in the medical management of rheumatoid arthritis (RA), it remains a chronic, painful and disabling condition. RA symptoms guide treatment, prompt physician visits, and affect patients' quality of life and productivity. However, patients with comparable disease severity differ widely in their symptoms and psychological factors partially explain this inter-individual variability in symptoms. ${ }^{1-} 6$. The statistical correlation between pain and objective measures of disease severity is modest, ranging between 0.23 and 0.527 , and successful treatment of the disease process is not necessarily accompanied by improvement in symptoms 8 . RA symptoms result from the interplay of soma and psyche, and thus psychological factors contribute to symptoms and disability. This suggests a role for psychosocial treatments in the long-term management of arthritis symptoms ${ }^{9}$.

The literature on psychosocial and psychoeducational treatments as adjuncts to medical therapy indicates that they reduce RA symptoms, disability, and role impairment, and improve coping. Most of these therapies consist of varying combinations of three basic elements: (1) Education, encompassing information and explanation about the disease, its symptoms and its treatment, joint protection, pacing of activities, use of heat and cold, and graduated exercise; (2) Stress reduction programs incorporating relaxation response training, progressive muscle relaxation, mindfulness meditation, and biofeedback; (3) Cognitive/ behavior therapy to enhance coping skills with techniques such as altering pain-related cognitions, attention refocusing and distraction, goal-setting and self-reinforcement, and pain coping strategies. Several meta-analyses indicate that these interventions are effective, but their comparability and durability remain unclear ${ }^{10-} 12$.

The current study was designed as a randomized, controlled, intervention trial of the longterm benefits of these three psychosocial treatments for rheumatoid arthritis: cognitive/ behavior therapy, relaxation response training, and a patient education program. We assessed and compared their effects on symptoms, disability and role impairment. We hypothesized that the patients undergoing both the cognitive behavior therapy and the relaxation response would have significantly fewer symptoms and less role impairment than those undergoing the arthritis education program.

\section{METHODS}

\section{Study Design}

Eligible subjects completed a baseline interview and were then randomized to one of three treatment conditions: Cognitive-behavior therapy (CBT), relaxation response training (RR), or arthritis education (AE), the latter designed to serve as an ethically justifiable attention control condition. To avoid biasing the subjects, none of the three treatment modalities was ever specifically identified as the control treatment. All treatment was conducted in groups of 5-8 patients, over an 8-12 week period, followed by monthly booster telephone calls. Outcomes were assessed with in-person interviews immediately following treatment, and 6 and 12 months later. Data were gathered by research assistants blind to treatment modality, and the therapists had no role in data collection. The primary outcome was the change in RA symptoms between the baseline and 12 month assessments. The protocol was approved by the Partners Human Research Committee and all subjects provided written informed consent. 


\section{Methods and Procedures}

Patients were enrolled between June, 2002 and September, 2005. Long-term follow-up was completed in October, 2006. The baseline battery included self-report questionnaires, a grip strength test and a walking time test, followed by a standardized joint examination and the collection of a blood sample. Once five subjects were accrued, this group was randomly assigned by computer to one of the three treatment modalities. However, after accruing 127 patients, unequal numbers of patients across the treatment arms led us to an unbalanced randomization for the remaining 41 patients in order to restore balance.

\section{Subjects and Setting}

Most subjects were identified through the hospital's computerized patient registry, which was queried for all patients with a diagnosis of RA who had had a visit within the previous year. A smaller number of subjects volunteered for the study in response to public announcements and advertisements.

Patients who were between 20 and 75 years old, met ACR criteria for rheumatoid arthritis, and were fluent and literate in English were eligible. There were three exclusion criteria: fibromyalgia; serious medical comorbidity likely to progress substantially or cause death in the ensuing 12 months; and currently receiving psychosocial treatment for RA.

\section{Treatment Conditions}

The CBT consisted of 12 , tightly manualized, $60-75$ minute sessions. It was a slightly modified and shortened version of the treatment program of Bradley ${ }^{13-15}$ to help patients develop effective coping strategies, enhance self-efficacy and personal control, and modify maladaptive behaviors that maintain symptoms and disability. Techniques taught included problem solving and goal setting, relabeling and reframing of symptoms, enhanced awareness of pain behaviors, activity pacing, and distraction and attention refocusing. Homework was given at the end of each session and reviewed at the beginning of the following session.

The RR consisted of 8, 50-60 minute sessions. Relaxation training has been used to reduce the pain associated with a variety of medical conditions 16,17 . Recent work has begun to illuminate possible changes in gene expression resulting from relaxation training that may relate to long-term physiological effects ${ }^{18}$. The RR in this study included the following topics: the relaxation response - psycho-physiological and cognitive aspects; diaphragmatic breathing; progressive muscle relaxation (PMR); and generalization of relaxation response skills to symptom management. The protocol was tightly manualized, standardized, and largely, based upon the Jacobsenian technique ${ }^{19}, 20$. Patients were given audiotapes that included the full PMR technique, were assigned daily practice, and were instructed to record their activities, which were reviewed in subsequent treatment sessions.

Patients in the AE group received 8, 50 minute, scripted talks and printed material about RA and its treatment. The sessions were didactic in tone, no specific recommendations about behavioral or attitudinal change were made, no skills training was provided, and no active, problem-solving was included. Topics covered included RA pathophysiology; arthritis medication and therapies; physical exercise and activity; nutrition and diet; and the nature of stress. Group support was not specifically encouraged, but did occur spontaneously.

For all three treatments, brief booster phone calls occurred 2 and 4 weeks following the final sessions and then 2, 3, 6, 9 and 12 months later. These calls focused on review of information learned previously and consolidation of skills, maintenance of gains, problem solving, and relapse prevention. Each therapist each administered all three treatments. 
Therapists had master's or doctoral degrees and prior training and experience conducting cognitive/behavior therapy and relaxation response training. They underwent regular, ongoing supervision throughout the study. Treatment fidelity was established with blind ratings of randomly selected audio- taped treatment sessions and was found to be high.

\section{Assessment}

Rheumatoid Arthritis Pain and Other Symptoms-Pain and symptoms were the primary outcome measures. The Rheumatoid Arthritis Symptom Questionnaire (RASQ) is a 14-item, face-valid, self-report questionnaire. It includes pain (2 items), stiffness, swelling, restriction of movement, fatigue, poor appetite, difficulty sleeping and malaise. These are rated on a $10 \mathrm{~cm}$ visual analog scale from "no" distress to the "worst possible" distress. Visual analog self-rating is the most widely employed method for measuring pain and other symptoms and this method has been shown to be reliable and content valid ${ }^{10,} 21^{-} 23$

Role Impairment and Disability-The Arthritis Impact Measurement Scale (AIMS-2) is a widely used self-report measure of several domains of functioning with rheumatic disease, including mobility, walking and bending, self-care tasks, household tasks, social activities, and work ${ }^{24-} 26$. It is valid and sensitive to change and has excellent internal consistency and reliability $24,26,27$.

Disease Severity and Disease Activity-There is no generally agreed upon standard for assessing RA disease activity and severity, and various indices including laboratory parameters, physical findings, and symptoms are used. Since we were interested in the divergence between subjective symptoms and demonstrable objective disease, we did not want to confound the assessment of disease severity with symptom reports. We therefore used erythrocyte sedimentation rate (ESR) ${ }^{28}$, 29 and standardized physician ratings of joint swelling to index disease severity and activity. ESR was chosen because of its demonstrated superior sensitivity 30 , and was determined using the Westergren method.

Joint swelling is an index of overall disease activity ${ }^{31}$. It was rated on a four point scale with a standardized, 28-joint physical examination ${ }^{32-34}$ by a rheumatologist who was blind to the patient's treatment status. This method yields reproducible results which are associated with ESR results and immunological measures ${ }^{32-34}$. Joint tenderness was also rated, but was not included in these analyses because it is confounded by the patient's subjective self-report and is not therefore a pure measure of objective disease severity 28 .

Grip strength was tested with a hydraulic hand dynamometer. Three readings were obtained for each hand and then averaged ${ }^{35,36}$. Walking time was tested by asking the patient to walk 65 feet at his/her "usual pace," and timing this with a stop watch 37,38 .

Medications-The patient's current arthritis medication regimen was obtained at each assessment. Medications were then grouped into analgesics, non-steroidal anti-inflammatory agents, COX-2 inhibitors, disease-modifying anti-rheumatic drugs (DMARDs), biological response modifiers, steroids, and antidepressants prescribed for pain. These were then arrayed hierarchically into 4 classes according to the aggressiveness of treatment and degree of associated risk: symptomatic drugs, steroids, DMARDS, and biological response modifiers.

Psychological Distress-Depression is prevalent in RA and has a major influence on pain and role impairment and disability $39^{-41}$. We assessed psychological symptoms using the Rand Mental Health Inventory (MHI), a self-report inventory of common psychological symptoms, that has a high degree of internal consistency and external validity $42-45$. It does 
not include physical or psychosomatic symptoms. We employed the 18 -item version, containing anxiety and depression subscales.

\section{Statistical Methods}

The a priori specified primary outcome measure was the change in the RASQ score at 12 months. Using an intention to treat strategy, patients who did not complete the RASQ at 12 months had their last observations carried forward. To insure balance, the following covariates were chosen before analysis: therapist, age, gender, white versus non-white, married versus not, education, time since RA diagnosis, medication use, number of swollen joints, and sedimentation rate. All of these covariates, plus the baseline RASQ score, were included in a linear regression with the change in total RASQ score as the outcome and the 3 -group treatment variable as the primary predictor. If the 3-group F-test for treatment was significant at $\mathrm{p}<.05$, then pairwise tests were carried out with a Bonferroni-adjusted $\mathrm{p}$-value of 0.025 . The robustness of the conclusions was investigated by repeating the analyses without covariate adjustment, and by analyzing only the subset of patients who completed the 12-month follow-up assessment.

Seven secondary outcomes were analyzed in the same way: RASQ pain scores; MHI depression and anxiety scores; and AIMS mobility, household chores, self care, and social activities scores. Two additional outcomes, walk time and grip strength, were also analyzed to examine objective measures of physical functioning that we did not expect to benefit from treatment.

Secondary analyses were carried out to examine treatment effects immediately after treatment and 6-months later, as well as to examine symptom progression over time. A repeated measures linear regression model was constructed using the MIXED procedure, allowing an unstructured correlation matrix to account for dependence in the serial followup measures. All repeated measures models included the covariates listed above for the 12month analyses, and time was included as a 4-category predictor. The initial model included interaction terms between treatment and time and a partial F-test was used to decide whether treatment differences occurred at any time during follow-up. If the test of interaction was non-significant, the interaction terms were removed from the model and the effect of time was assessed using a partial F-test. The last-observation-carried-forward strategy was used.

Effect sizes were calculated to depict changes in outcome over time. Mean changes were adjusted for the covariates listed above through linear regression models with change-frombaseline as the outcome variable. The adjusted mean changes were then standardized by dividing by the standard deviation at baseline.

\section{RESULTS}

Figure 1 presents the flow of patients through the study. Of the 1680 patients initially screened for eligibility, 168 were enrolled and randomized to one of the three treatment arms.

The 3 treatment groups are compared at baseline in Table 1, where it can be seen that the study population is predominately female, Caucasian, and middle-aged. Their arthritis is chronic, having been present for approximately 13 years. The three groups did not differ significantly at baseline.

\section{Longitudinal Change}

Table 2 presents the 12-month treatment outcomes. Pain improved significantly with RR and $\mathrm{AE}$ and showed a non-significant positive trend with CBT. Overall symptoms (total RASQ) 
were significantly improved with $\mathrm{AE}$ and $\mathrm{CBT}$, and showed a non-significant positive trend with RR. Despite a few isolated instances of improved role functioning, there was no overall benefit. Nor did depression or anxiety improve with any of the treatments. As Table 2 also shows, there were no significant or meaningful differences across the three treatment arms.

Table 3 shows the time course of treatment effects. For all of the outcomes, the time-bytreatment interaction p-values are non-significant, indicating that changes in outcome over time were similar across the 3 arms, supporting our prior conclusion that there were no differences across treatment groups. There were no significant differences in the arthritis medication regimens of the three treatment groups. Thus the mean number of medications per patient at baseline and follow-up did not differ across the three treatment arms. Nor did the proportion of patients taking DMARDs or biologic response modifiers differ significantly at baseline or follow-up across the three treatment arms.

When the results are aggregated across treatment groups, there were significant improvements from baseline through follow-up in four of our outcomes. Table 3 indicates significant improvements in the total RASQ scores ( $\mathrm{p}<.001)$, in the RASQ pain scores $(\mathrm{p}<$. $001)$, in the AIMS self-care scores $(\mathrm{p}=.02)$, and the AIMS social activities scores $(\mathrm{p}=.01)^{1}$. Finally, walk times actually worsened significantly over time $(\mathrm{p}=.01)$ and grip strength did not change over time.

These improvements over time, and their consistency across treatment groups, is shown more clearly in Figure 2. Effect sizes are displayed for outcome variables with significant changes over time (RASQ pain, RASQ total symptoms, and AIMS social activities), as well as for one non-significant outcome (AIMS household chores) for comparison. The effect sizes for pain and for total symptoms displayed in Figure 2a range between 0.26 and 0.35 for post-treatment. They are significant for all treatment groups. These are maintained at 6 month follow-up for all symptoms and treatment groups except the total score in the RR group. At 12 month follow-up all effect sizes remained positive in the small to medium range ${ }^{46}$. However pain and total symptoms in the CBT group and pain in the RR group failed to reach significance. The psychosocial outcome variables show a more heterogeneous picture at post-treatment (see Figure 2b). At 6 month follow-up all groups show positive improvements on the AIMS social activities and household chores scales. Significant positive treatment effects result only for AIMS social activities at 12 month follow-up in the CBT and the RR treatment arms with effect sizes of 0.21 and 0.37 respectively.

\section{Efficacy Results}

A substantial number of patients did not attend all treatment sessions. Significantly fewer of the patients randomized to CBT, 57\%, completed at least 8 of the 12 therapy sessions, while $80 \%$ and $83 \%$ of patients randomized to relaxation response or arthritis education, respectively, completed at least 6 of their prescribed 8 sessions. In order to understand whether the negative findings in the intent-to-treat analyses could have been due to the disproportionately large number of CBT patients who did not complete their treatment, we carried out a secondary completers analysis of the 114 patients who attended at least $80 \%$ of their treatment sessions. There were no significant differences across treatment arms for any of our 10 outcome measures. Completers had significantly more improvement in anxiety $(\mathrm{p}=.01)$ and AIMS mobility $(\mathrm{p}=.046)$ than did non-completers.

\footnotetext{
${ }^{1}$ Since depression and anxiety scores were only measured at baseline and 12 months, data were already shown in Table 2 and although further adjusted analyses suggested improvement over time, this did not reach statistical significance [depression $=.35$ point improvement ( $\mathrm{se}=.23), \mathrm{p}=.12$; anxiety $=.15$ point improvement $(\mathrm{se}=.23), \mathrm{p}=.52]$.
} 


\section{DISCUSSION}

We found that three psychosocial treatments targeting rheumatoid arthritis symptoms were statistically and clinically beneficial, with treatment effect sizes in the small to moderate range. Our primary hypothesis was not supported, as there were no significant differences in treatment outcome across the three treatment modalities. These effects were apparent immediately following treatment and were generally sustained 6 and 12 months later, though slightly attenuated. The treatment was beneficial for pain and other arthritis symptoms, and for social and self-care ability, but not for mobility or the performance of household chores, or for depression or anxiety or physical function. Because depression and anxiety did not improve, this suggests that they did not mediate the treatment effect, i.e., that somatic symptom improvement did not result from a lessening of psychological distress.

These findings are compatible with the existing literature, which indicates that modest but meaningful benefits, on the order of those achieved with symptomatic RA treatments such as NSAIDs, can be achieved over and above standard medical therapy. However, we did not find a treatment effect on anxiety or depression, which some other studies have reported. For example, recent studies have found that cognitive behavior therapy and mindfulness meditation both produce significant improvements not only in pain and well-being, but also on psychological distress and coping 9,47 . Astin et al ${ }^{11}$ analyzed 25 randomized, controlled trials of psychosocial treatments for rheumatoid arthritis. The mean follow-up interval was 8.6 months. The pooled treatment effect size for pain immediately after treatment was 0.22 $(\mathrm{p}=.003)$ but at follow-up it was $0.06(\mathrm{p}=\mathrm{ns})$; the pooled treatment effect size for functional disability post-treatment was $0.27(\mathrm{p}=.001)$, but at follow-up it was 0.12 , again not significant. Thus the benefits of treatment for pain and disability were found to attenuate over time. These treatment effects were over and above the benefits of standard rheumatological care.

Dixon et al ${ }^{10}$, in a more recent meta-analysis of 27 studies, examined only the effects immediately following treatment. They found a mean post-treatment effect size of 0.18 (p $<.01)$ for pain, $0.20(\mathrm{p}<.01)$ for depression, $0.28(\mathrm{p}<.01)$ for anxiety, and $0.15(\mathrm{p}<.01)$ for physical function. No statistically significant post-treatment benefit was seen for symptoms other than pain, such as stiffness and fatigue. The authors noted that these effect sizes approximated those seen with non-steroidal anti-inflammatory agents. In a metaanalysis of patient education interventions, Superio-Cabuslay ${ }^{12}$ found the weighted average effect size for pain was 0.17 and for functional disability was 0.18 . The average effect size for tender joints was .028. The median duration of these trials was 4 months. As noted above, these represent the additional effects of education beyond those achieved with standard medical care.

In the current study, the treatment effect did not differ significantly across the three modalities. Arthritis education (AE), which was originally intended as an "attention control" treatment, provided the non-specific therapeutic elements of encouragement, positive expectations, an enhanced sense of efficacy, and social support (indeed, several of the AE groups continued communicating and meeting with each other after the study ended). AE did not however include any of the more specific, active ingredients of the other two treatments, and there was no problem solving or skills training. However, a substantial literature indicates that education and information alone do provide statistically significant and clinically meaningful benefit ${ }^{48-} 52$.

A true no-treatment control group was not included in our study design because patient education is now an accepted part of optimal RA treatment. Design considerations also pushed us toward a potent "attention control" since such treatments must be interesting and 
substantive enough to retain the participants, thereby avoiding differential attrition. However, the absence of a true no treatment control group makes it difficult to determine whether all three treatments were equally effective or equally ineffective. Several lines of reasoning suggest the former. First, the literature contains many studies with no treatment control groups in patient populations similar to ours, and no significant improvement was found in RA symptoms, impairment, or psychological distress over follow-up intervals up to 1 year ${ }^{15,20,53-61}$. Second, none of our treatment groups improved in disease severity at any of the time points, so the symptom improvement cannot be attributed to improved RA. Third, the effect sizes we observed for all three treatments are comparable to those reported with other active psychosocial treatments for rheumatoid arthritis pain, which tend to be between .25 and $.40^{10-12}$. Finally, the time course of our treatment effect is unlikely to result from a regression to the mean where one would expect gradual, progressive improvement over time rather than the immediate decline in symptoms followed by a constant, stable level of symptoms over time, as occurred in our study.

The study has a number of limitations. First, the sociodemographic and clinical characteristics of our sample limit generalization. Most patients were in ongoing care at an academic medical center and as such may not be representative of the reference population. Second, the medication regimens were only ascertained at the follow-up points and not continuously in between. Third, we did not obtain x-ray evidence of disease severity or additional inflammatory markers of disease activity such as cytokine levels. Finally, because of sampling variability, it is possible that CBT had a beneficial effect that we were unable to detect. However, based on $95 \%$ confidence intervals for our 12-month comparisons, it is very unlikely that CBT could be superior to patient education by more than 0.67 points on the RASQ pain scale (a standardized change of $0.26 \mathrm{sd}$ ), nor more than 0.42 points on the RASQ total symptom score (a standardized change of $0.23 \mathrm{sd}$ ). Performing an additional study to rule-out such a small advantage of CBT over patient education would require a sample size of approximately 300 patients per arm.

Although these treatment benefits are modest, they were achieved over and above optimal medical therapy. Thus they constitute an effective augmentation to standard medical therapy, achieved in a chronically ill population who had been sick for over 12 years; it is possible that the benefit might be greater in patients with early disease since there is likely to be greater flexibility and latitude for behavior and cognitive change early in the course of illness when coping styles have not yet become rigidified and less adaptable. Finally, the fact that all three treatments were comparable suggests that the less expensive, complex, and time-consuming psychosocial treatments may be the preferable adjunct to standard rheumatological care.

\section{Acknowledgments}

We wish to thank Francis J. Keefe, Ph.D., and Laurence A. Bradley, Ph.D, for their guidance and consultation. The research team included Alexis C. Lawrence, and Jessica Payne-Murphy. Susan L. Rose prepared the manuscript.

Supported by research grant R01 AR 4701401 from the National Institute of Arthritis \& Musculoskeletal and Skin Diseases

\section{Reference List}

1. Papageorgiou AC, Badley EM. The quality of pain in arthritis: the words patients use to describe overall pain and pain in individual joints at rest and on movement. J Rheumatol 1989;16:106-112. [PubMed: 2715997]

2. Charter RA, Nehemkis AM, Keenan MA, Person D, Prete PE. The nature of arthritic pain. Br J Rheumatol 1985;24:53-60. [PubMed: 3978366] 
3. Moldofsky H, Chester WJ. Pain and mood patterns in patients with rheumatoid arthritis: a prospective study. Psychosom Med 1970;32:309-318. [PubMed: 5419612]

4. Flor H, Turk DC. Chronic back pain and rheumatoid arthritis: predicting pain and disability from cognitive variables. J Behav Med 1988;11:251-265. [PubMed: 2971810]

5. Hagglund KJ, Haley WE, Reveille JD, Alarcon GS. Predicting individual differences in pain and functional impairment among patients with rheumatoid arthritis. Arthritis Rheum 1989;32:851-858. [PubMed: 2751719]

6. DeVellis R, DeVellis B, Sauter S, Harring K, Cohen J. Predictors of pain and functioning in arthritis. Health Education Research 1986;1:61-67.

7. Callahan LF, Brooks RH, Summey JA, Pincus T. Quantitative pain assessment for routine care of rheumatoid arthritis patients, using a pain scale based on activities of daily living and a visual analog pain scale. Arthritis Rheum 1987;30(6):630-636. [PubMed: 3606681]

8. Dwosh IL, Giles AR, Ford PM, Pater JL, Anastassiades TP. Plasmapheresis therapy in rheumatoid arthritis. New Engl J Med 1983;308:1124-1129. [PubMed: 6339939]

9. Zautra AJ, Davis MC, Reich JW, Nicassio P, Tennen H, Finan P, et al. Comparison of cognitive behavioral and mindfulness meditation interventions on adaptation to rheumatoid arthritis for patients with and without history of recurrent depression. J Consult Clin Psychol 2008;76:408-421. [PubMed: 18540734]

10. Dixon KE, Keefe FJ, Scipio CD, Perri LM, Abernethy AP. Psychological interventions for arthritis pain management in adults: A meta-analysis. Health Psychol 2007;26:241-250. [PubMed: 17500610]

11. Astin JA, Beckner W, Soeken K, Hochberg MC, Berman B. Psychological interventions for rheumatoid arthritis: A meta-analysis of randomized controlled trials. Arthr \& Rheum 2002;47:291-302. [PubMed: 12115160]

12. Superio-Cabuslay E, Ward M, Lorig K. Patient education interventions in osteoarthritis and rheumatoid arthritis: A meta-analytic comparison with nonsteroidal antiinflammatory drug treatment. Arthritis Care Res 1996;9:292-301. [PubMed: 8997918]

13. Bradley LA, Young LD, Anderson KO, Turner RA, Agudelo CA, McDaniel LK, et al. Effects of psychological therapy on pain behavior of rheumatoid arthritis patients: treatment outcome and six-month followup. Arthritis Rheum 1987;30:1105-1114. [PubMed: 3314877]

14. Bradley LA, Alberts KR. Psychological and behavioral approaches to pain management for patients with rheumatic disease. Rheum Dis Clin North Am 1999;25:215-232. [PubMed: 10083965]

15. Bradley, LA.; Young, LD.; Anderson, KO.; Turner, RA.; Agudelo, CA.; McDaniel, LK., et al. Effects of cognitive-behavioral therapy on rheumatoid arthritis pain behavior: one-year follow-up. In: Dubner, R.; Gebhart, GF.; Bond, MR., editors. Proceedings of the Vth World Congress on Pain; New York: Elsevier Science; 1988. p. 310-314.

16. NIH Technology Assessment Panel on Integration of Behavioral and Relaxation Approaches Into the Treatment of Chronic Pain and Insomnia. Integration of behavioral and relaxation approaches into the treatment of chronic pain and insomnia. JAMA 1996;276:313-318. [PubMed: 8656544]

17. Vickers A, Zollman C. Hypnosis and relaxation therapies. BMJ 1999;319:1346-1349. [PubMed: 10567143]

18. Dusek JA, Otu HH, Wohlhueter AL, Bhasin M, Zerbini LF, Joseph MG, et al. Genomic counterstress changes induced by the relaxation response. PLoS One 2008;3:e2576. [PubMed: 18596974]

19. Jacobsen, E. Progressive Relaxation. 2nd ed.. Chicago: University Press; 1938.

20. Lundgren S, Stenström CH. Muscle relaxation training and quality of life in rheumatoid arthritis. Scand J Rheumatol 1999;28:47-53. [PubMed: 10092165]

21. Scott J, Huskisson EC. Accuracy of subjective measurements made with or without previous scores - an important source of error in serial measurement of subjective states. Ann Rheum Dis 1979;39:558-559. [PubMed: 317238]

22. Huskisson EC. Measurement of pain. Lancet 1974;2:1127-1131. [PubMed: 4139420]

23. Huskisson, EC. Visual Analog Scales. In: Melzack, R., editor. Pain Measurement and Assessment. New York: Raven Press; 1983. p. 33-37. 
24. Meenan RF, Mason JH, Anderson JJ, Guccione AA, Kazis LE. AIMS2. The content and properties of a revised and expanded arthritis impact measurement scales health status questionnaire. Arthritis Rheum 1992;35:1-10. [PubMed: 1731806]

25. Meenan RF, Gertman PM, Mason JR, Dunaif R. The Arthritis Impact Measurement Scales: further investigations of a health status measure. Arthritis Rheum 1982;25:1048-1053. [PubMed: 7126289]

26. Anderson JJ, Firschein HE, Meenan RF. Sensitivity of a health status measure to short-term clinical changes in arthritis. Arthritis Rheum 1989;32:844-850. [PubMed: 2665756]

27. Meenan RF, Gertman PM, Mason JH. Measuring health status in arthritis: the Arthritis Impact Measurement Scales. Arthritis Rheum 1980;23:146-152. [PubMed: 7362665]

28. Wolfe F. The prognosis of rheumatoid arthritis: assessment of disease activity and disease severity in the clinic. Am J Med 1997;103 12S-18S.

29. Stucki G, Liang MH, Stucki S, Bruhlmann P, Michel BA. A self-administered rheumatoid arthritis disease activity index (RADAI) for epidemiological research. Arthritis Rheum 1995;38:795-798. [PubMed: 7779122]

30. Ward M. Relative sensitivity to change of the erythrocyte sedimentation rate and serum C-reactive protein concentration in rheumatoid arthritis. J Rheumatol 2003;31:884-895. [PubMed: 15124246]

31. van der Heijde DM, van't Hof MA, van Riel PL. Validity of single variables and composite indices for measuring disease activity in rheumatoid arthritis. Ann Rheum Dis 1992;51:177-181. [PubMed: 1550400]

32. Fuchs HA, Pincus T. Reduced joint counts in controlled clinical trials in rheumatoid arthritis. Arthritis Rheum 1994;37:470-475. [PubMed: 8147923]

33. Prevoo MLL, van't Hof MA, Kuper HH, van Leeuwen MA, van de Putte LBA, van Riel PL. Modified disease activity scores that include twenty-eight-joint counts. Arthr \& Rheum 1995;38:44-48. [PubMed: 7818570]

34. Smolen JS, Breedveld FC, Eberl G, Jones I, Leeming M, Wylie GL, et al. Validity and reliability of the twenty-eight-joint count for the assessment of rheumatoid arthritis activity. Arthr \& Rheum 1995;38:38-43. [PubMed: 7818569]

35. Lee P, Baxter A, Dick WC, Webb J. Assessment of grip strength measurement in rheumatoid arthritis. Scand J Rheumatol 1973;3:17-23. [PubMed: 4609126]

36. Pincus T, Callahan LF. Rheumatology function tests: Grip strength, walking time, button test and questionnaires document and predict longterm morbidity and mortality in rheumatoid arthritis. $\mathbf{J}$ Rheumatol 1992;19:1051-1057. [PubMed: 1512758]

37. Deohar SD, Dick WC, Hodgkinson R, Buchanan WW. Measurement of clinical response to antiinflammatory drug therapy in rheumatoid arthritis. Q J Med 1973;42:387-401. [PubMed: 4594449]

38. Pincus, T.; Callahan, LF.; Brooks, RH. Quantitative nonlaboratory measures to monitor and predict the course of rheumatoid arthritis. In: Ehrlich, GE., editor. Rehabilitation Management of Rheumatic Conditions. Baltimore: Williams and Wilkins; 1986. p. 45-64.

39. Smith TW, Christensen AJ. Positive and negative affect in rheumatoid arthritis: Increased specificity in the assessment of emotional adjustment. Ann Behav Med 1996;18:75-78.

40. Smith TW, Peck JR, Ward JR. Helplessness and depression in rheumatoid arthritis. Health Psychol 1990;9:377-389. [PubMed: 2373064]

41. Smith TW, Christiansen AJ, Peck JR, Ward JR. Cognitive Distortion, Helplessness, and Depressed Mood in Rheumatoid Arthritis: A Four-Year Longitudinal Analysis. Health Psychol 1994;13:213217. [PubMed: 8055856]

42. Ware, JE.; Johnston, SA.; Davies-Avery, A., et al. Mental Health. Santa Monica, CA: RAND Corp; 1979. Conceptualization and measurement of health for adults in the Health Insurance Study.

43. Ware JE, Manning WG Jr, Duan N, Wells KB, Newhouse JP. Health Status and the use of outpatient mental health services. Am Psychol 1984;39:1090-1100. [PubMed: 6507983]

44. Veit CT, Ware JE. The structure of psychological distress and well-being in general populations. J Consult Clin Psychol 1983;51:730-742. [PubMed: 6630688] 
45. Hays RD, Stewart AL. The structure of self-reported health in chronic disease patients. J Consult Clin Psychol 1990;2:22-30.

46. Cohen, J. Statistical Power Analyses for the Behavioral Sciences. 2nd ed.. Hillsdale, NJ: Laurence Erlbaum Associates; 1988.

47. Pradhan EK, Baumgarten M, Langenberg P, Handwerger B, Kaplan Giplin A, Magyari T, et al. Effect of mindfulness-based stress reduction in rheumatoid arthritis patients. Arthritis Care Res 2007;57:1134-1142.

48. Taal E, Riemsma RP, Herman LMB, Seydel ER, Rasker JJ, Wiegman O. Group education for patients with rheumatoid arthritis. Patient Ed and Counsel 1993;20:177-187.

49. Lorig K, Lubeck D, Kraines RG, Seleznick M, Holman HR. Outcome of self-help education for patients with arthritis. Arthritis Rheum 1985;28:680-685. [PubMed: 4004977]

50. Lorig KR, Mazonson PD, Holman HR. Evidence suggesting that health education for selfmanagement in patients with chronic arthritis has sustained health benefits while reducing health care costs. Arthritis Rheum 1993;36:439-446. [PubMed: 8457219]

51. Lorig K, Holman H. Arthritis self-management studies: a twelve-year review. Health Educat Quat 1993;20:17-28.

52. Goeppinger J, Arthur MW, Baglioni AJ, Brunk SE, Brunner CM. A reexamination of the effectiveness of self-care education for patients with rheumatoid arthritis. Arthr \& Rheum 1989;32:706-716. [PubMed: 2735963]

53. Scholten C, Brodowicz T, Graninger W, Gardavsky I, Pils K, Pesau B, et al. Persistent functional and social benefit 5 years after a multidisciplinary arthritis training program. Arch Phys Med Rehabil 1999;80:1282-1287. [PubMed: 10527088]

54. Maisiak R, Austin JS, West SG, Heck L. The effect of person-centered counseling on the psychological status of persons with systemic lupus erythematosus or rheumatoid arthritis. A randomized, controlled trial. Arthritis Care Res 1996;9:60-66. [PubMed: 8945114]

55. Radojevic V, Nicassio PM, Weisman MH. Behavioral intervention with and without family support for rheumatoid arthritis. Behav Ther 1992;23:13-30.

56. Leibing E, Pfingsten M, Bartmann U, Rueger U, chuessler G. Cognitive-Behavioral treatment in unselected rheumatoid arthritis patients. Clin J Pain 1999;15:58-66. [PubMed: 10206568]

57. Evers AWM, Kraaimaat FW, van Riel PLCM, de Jong AJL. Tailored cognitive-behavioral therapy in early rheumatoid arthritis for patients at risk: a randomized controlled trial. Pain 2002;100:141153. [PubMed: 12435467]

58. Sharpe L, Sensky T, Timberlake N, Ryan B, Allard S. Long-term efficacy of a cognitive behavioural treatment from a randomized controlled trial for patients recently diagnosed with rheumatoid arthritis. Rheumatol 2003;42:435-441.

59. O'Leary A, Shoor S, Lorig K, Holman HR. A cognitive-behavioral treatment for rheumatoid arthritis. Health Psychol 1988;7:527-544. [PubMed: 3063517]

60. Lindroth Y, Brattström M, Bellman I, Ekestaf Y, Olofsson Y, Strömbeck B, et al. A problem-based education program for patients with rheumatoid arthritis: Evaluation after three and twelve months. Arthritis Care Res 1997;10:325-332. [PubMed: 9362599]

61. Parker JC, Smarr KL, Buckelew SP, Stucky-Ropp RC, Hewett JE, Johnson JC, et al. Effects of stress management of clinical outcomes in rheumatoid arthritis. Arthritis Rheum 1995;38:18071818. [PubMed: 8849353] 


\section{$\underline{\text { Recruitment and Follow-up }}$}

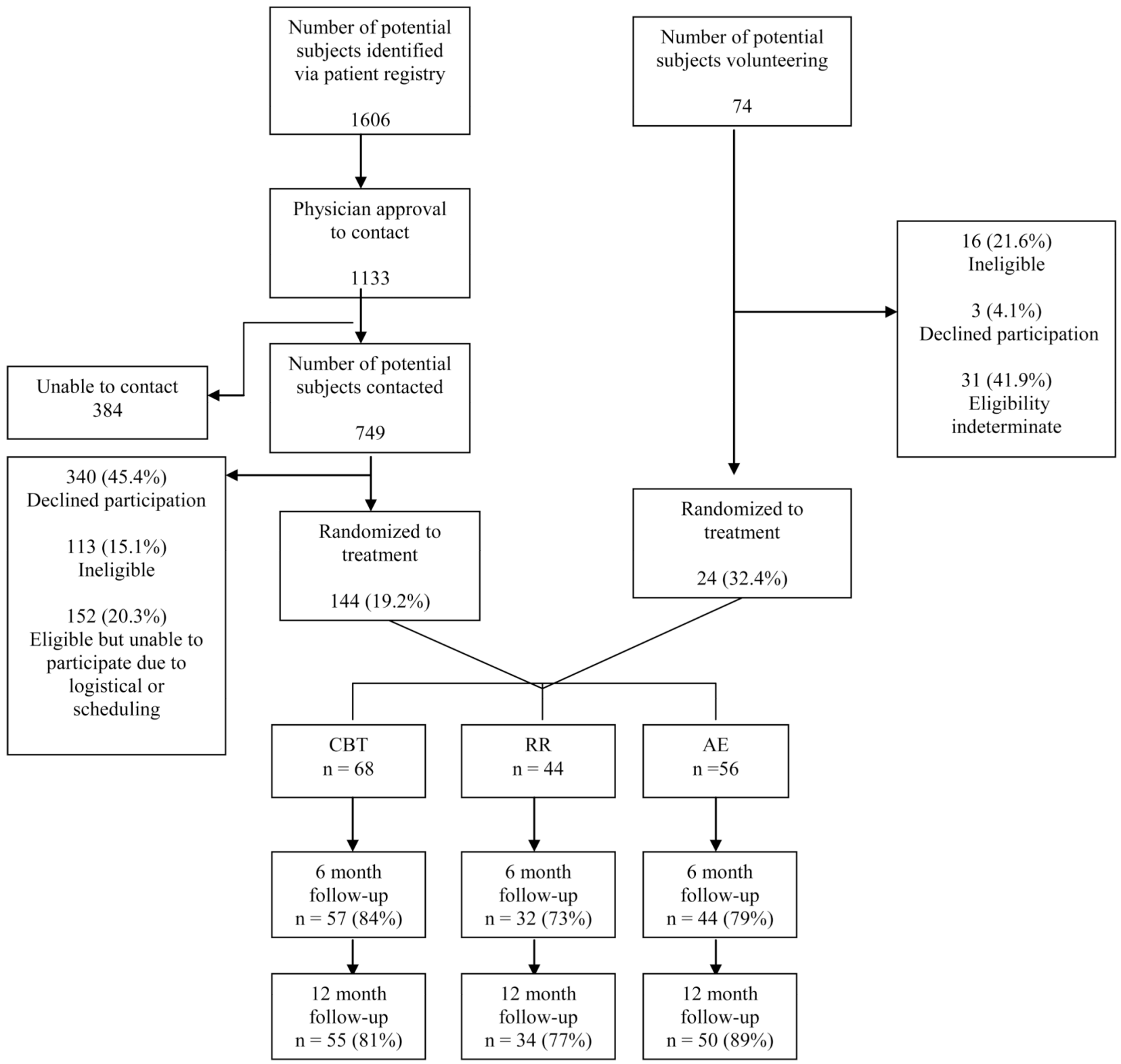

Figure 1.

Flow Chart for patient recruitment and follow-up 

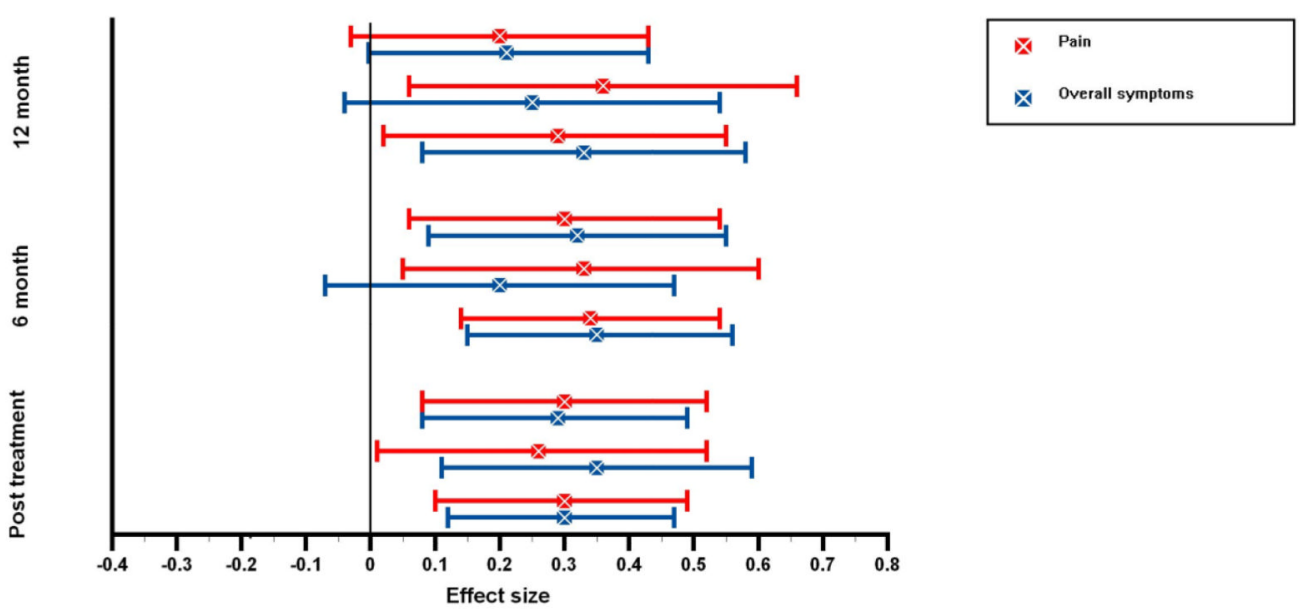

Figure 2a
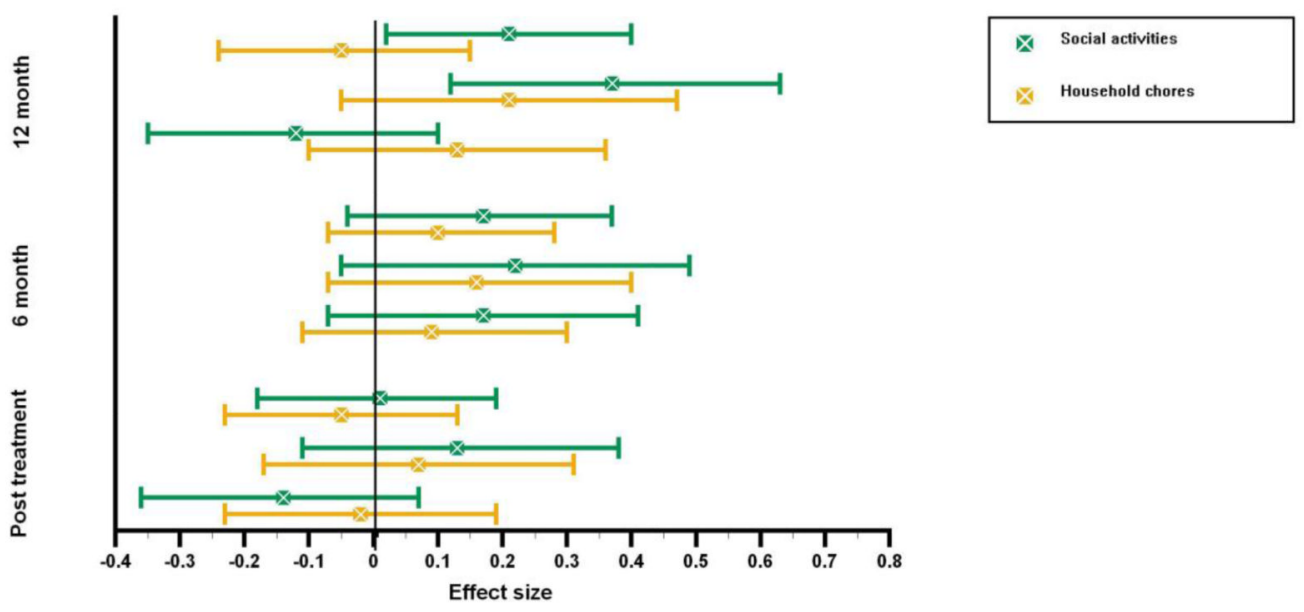

Figure 2b

Figure 2.

Figure 2a Treatment gains over time for arthritis pain and arthritis total symptoms.

Standardized effect sizes are displayed with $95 \%$ confidence intervals for changes from baseline to post-treatment, 6-months and 12-months.

Figure 2b Treatment gains over time for social activities and household chores.

Standardized effect sizes for changes in social activities and household chores from baseline to 6-months and 12-months. 
Table 1

Baseline Characteristics: demographics, disease severity, and medication

\begin{tabular}{|c|c|c|c|c|}
\hline \multirow[b]{2}{*}{ Characteristic } & \multicolumn{3}{|c|}{ Treatment Arms } & \multirow[b]{2}{*}{$p^{a}$} \\
\hline & CBT & $\mathbf{R R}$ & $\mathbf{A E}$ & \\
\hline Sample size & $\mathrm{n}=68$ & $\mathrm{n}=44$ & $\mathrm{n}=56$ & \\
\hline Age in years $(M+S D)$ & $54.3(13.1)$ & $54.0(12.3)$ & $51.9(13.4)$ & .59 \\
\hline Years since diagnosis $(\mathrm{M}+\mathrm{SD})$ & $12.4(11.3)$ & $13.9(10.2)$ & $14.1(13.1)$ & .54 \\
\hline Gender ( $\%$ female) & 90 & 82 & 87 & .48 \\
\hline Race $(\%)$ & & & & .66 \\
\hline white & 85 & 75 & 77 & \\
\hline black & 9 & 14 & 16 & \\
\hline other & 6 & 11 & 7 & \\
\hline Education (\%) & & & & .63 \\
\hline high school & 21 & 11 & 11 & \\
\hline some college & 19 & 25 & 18 & \\
\hline college & 26 & 18 & 29 & \\
\hline graduate school & 34 & 45 & 43 & \\
\hline Martial status (\%) & & & & .85 \\
\hline married & 51 & 48 & 46 & \\
\hline single & 19 & 23 & 25 & \\
\hline widowed/divorced & 30 & 29 & 29 & \\
\hline Receiving disability (\%) & 29 & 23 & 23 & .68 \\
\hline Currently employed (\%) & 50 & 57 & 64 & .28 \\
\hline \multicolumn{5}{|l|}{ Disease severity $(\mathrm{M}+\mathrm{SD})$} \\
\hline Swollen joints & $3.3(4.0)$ & $5.0(6.0)$ & $4.0(3.6)$ & .22 \\
\hline Erythrocyte sedimentation rate & $23.2(16.2)$ & $23.4(21.1)$ & $28.1(19.5)$ & .23 \\
\hline Walk time & $14.6(3.9)$ & $16.3(6.9)$ & $16.1(5.1)$ & .11 \\
\hline Grip Strength dominant hand & $33.0(21.4)$ & $34.1(20.6)$ & $29.9(19.4)$ & .55 \\
\hline Grip Strength non-dominant hand & $32.0(20.6)$ & $30.8(20.3)$ & $26.0(20.3)$ & .16 \\
\hline \multicolumn{5}{|l|}{ Medications (\%) } \\
\hline Symptomatic drugs & 75 & 91 & 77 & .09 \\
\hline Steroids & 29 & 34 & 23 & .48 \\
\hline Disease-modifying anti-rheumatic drugs & 63 & 59 & 57 & .78 \\
\hline Biologic response modifiers & 44 & 36 & 50 & .39 \\
\hline Total medications $(\mathrm{M}+\mathrm{SD})$ & $2.7(1.5)$ & $2.6(1.3)$ & $2.5(1.2)$ & .78 \\
\hline
\end{tabular}

Note. Patient characteristics for each study arm are described using means and standard deviations for continuous measures and percentages for categorical measures $. \mathrm{CBT}=$ Cognitive behavioral therapy; $\mathrm{RR}=$ Relaxation response training; $\mathrm{AE}=$ Arthritis Education .

${ }^{a} \mathrm{P}$-values for the comparisons of the three groups are from Fisher exact tests for categorical variables and the rank-based Kruskal-Wallis test for continuous measures. 
Table 2

Outcomes for the three treatment groups at 12 month follow-up*

\begin{tabular}{|c|c|c|c|c|}
\hline & Baseline & 12-Months & $\begin{array}{l}\text { Change from } \\
\text { 12-Months to } \\
\text { baseline }\end{array}$ & $n$-yalue \\
\hline Outcome Measure & Mean (SE) & Mean (SE) & $\operatorname{Mean}^{a, b}(\mathrm{SE})$ & $\begin{array}{l}\text { Ior } \\
\text { change }\end{array}$ \\
\hline \multicolumn{5}{|l|}{ RASQ Pain (VAS: 1-10) } \\
\hline CBT & $3.8(.31)$ & $3.2(.31)$ & $-.51(.30)$ & .09 \\
\hline $\mathrm{RR}$ & $4.0(.37)$ & $3.2(.39)$ & $-.92(.39)$ & .02 \\
\hline $\mathrm{AE}$ & $4.0(.37)$ & $3.1(.34)$ & $-.74(.34)$ & .03 \\
\hline Between Groups $p$-value ${ }^{a}$ & & & & .70 \\
\hline \multicolumn{5}{|c|}{ RASQ Total Symptoms (VAS: 1-10) } \\
\hline CBT & $2.8(.21)$ & $2.4(.21)$ & $-.40(.21)$ & .053 \\
\hline $\mathrm{RR}$ & $3.3(.31)$ & $2.8(.32)$ & $-.46(.27)$ & .09 \\
\hline $\mathrm{AE}$ & $3.1(.25)$ & $2.4(.25)$ & $-.61(.24)$ & .01 \\
\hline Between Groups $p$-value ${ }^{a}$ & & & & .81 \\
\hline \multicolumn{5}{|l|}{ AIMS Mobility (1-5) } \\
\hline CBT & $1.6(.24)$ & $1.7(.26)$ & $+.23(.20)$ & .27 \\
\hline RR & $1.4(.28)$ & $1.0(.22)$ & $-.51(.27)$ & .06 \\
\hline $\mathrm{AE}$ & $1.5(.28)$ & $1.3(.23)$ & $-.11(.23)$ & .65 \\
\hline Between Groups $p$-value ${ }^{a}$ & & & & .09 \\
\hline \multicolumn{5}{|l|}{ AIMS Household Chores (1-5) } \\
\hline CBT & $1.5(.32)$ & $1.4(.30)$ & $+.11(.22)$ & .63 \\
\hline $\mathrm{RR}$ & $0.9(.22)$ & $0.8(.20)$ & $-.47(.29)$ & .11 \\
\hline $\mathrm{AE}$ & $1.6(.29)$ & $1.2(.22)$ & $-.29(.26)$ & .26 \\
\hline Between Groups $p$-value ${ }^{a}$ & & & & .24 \\
\hline \multicolumn{5}{|l|}{ AIMS Self Care (1-5) } \\
\hline CBT & $.46(.17)$ & $.51(.21)$ & $+.04(.17)$ & .81 \\
\hline $\mathrm{RR}$ & $.28(.10)$ & $.21(.09)$ & $-.51(.22)$ & .03 \\
\hline $\mathrm{AE}$ & $.99(.26)$ & $.46(.14)$ & $-.20(.20)$ & .32 \\
\hline Between Groups $p$-value ${ }^{a}$ & & & & .16 \\
\hline \multicolumn{5}{|l|}{ AIMS Social Activities (1-5) } \\
\hline CBT & $4.5(.21)$ & $4.2(.19)$ & $-.38(.18)$ & .03 \\
\hline $\mathrm{RR}$ & $4.5(.29)$ & $4.0(.27)$ & $-.67(.23)$ & .005 \\
\hline $\mathrm{AE}$ & $4.9(.24)$ & $5.0(.24)$ & $+.22(.20)$ & .28 \\
\hline Between Groups $p$-value ${ }^{a}$ & & & & .02 \\
\hline \multicolumn{5}{|l|}{ MHI Depression (0-20) } \\
\hline CBT & $5.1(.47)$ & $4.8(.47)$ & $-.29(.36)$ & .42 \\
\hline $\mathrm{RR}$ & $4.8(.54)$ & $4.5(.60)$ & $-.48(.47)$ & .31 \\
\hline $\mathrm{AE}$ & $4.8(.51)$ & $4.3(.55)$ & $-.32(.41)$ & .44 \\
\hline Between Groups $p$-value ${ }^{a}$ & & & & .95 \\
\hline
\end{tabular}




\begin{tabular}{|c|c|c|c|c|}
\hline & Baseline & 12-Months & $\begin{array}{l}\text { Change from } \\
\text { 12-Months to } \\
\text { baseline }\end{array}$ & \\
\hline Outcome Measure & Mean (SE) & Mean (SE) & $\operatorname{Mean}^{a, b}(\mathrm{SE})$ & $\begin{array}{l}\text { for } \\
\text { change }\end{array}$ \\
\hline \multicolumn{5}{|l|}{ MHI Anxiety (0-20) } \\
\hline CBT & $6.2(.49)$ & $6.1(.46)$ & $-.26(.35)$ & .46 \\
\hline RR & $6.1(.65)$ & $6.1(.62)$ & $-.05(.46)$ & .92 \\
\hline $\mathrm{AE}$ & $5.9(.47)$ & $5.7(.48)$ & $-.13(.41)$ & .75 \\
\hline Between Groups $p$-value ${ }^{a}$ & & & & .93 \\
\hline \multicolumn{5}{|c|}{$\begin{array}{l}\text { Walk time (seconds needed for } 65 \text { feet } \\
\text { at usual pace) }\end{array}$} \\
\hline CBT & $14.6(.48)$ & $15.8(.46)$ & $+1.0(.40)$ & .04 \\
\hline RR & $16.3(1.0)$ & $17.1(1.0)$ & $+0.6(.61)$ & .31 \\
\hline $\mathrm{AE}$ & $16.1(.70)$ & $17.9(.86)$ & $+2.3(.54)$ & $\mathrm{p}<.001$ \\
\hline Between Groups $p$-value ${ }^{a}$ & & & & .11 \\
\hline \multicolumn{5}{|c|}{$\begin{array}{l}\text { Grip strength, dominant hand (pounds } \\
\text { per square inch) }\end{array}$} \\
\hline CBT & $33(2.6)$ & $35(2.6)$ & $+2.2(1.3)$ & .09 \\
\hline RR & $34(3.1)$ & $35(3.4)$ & $+0.8(1.7)$ & .63 \\
\hline $\mathrm{AE}$ & $30(2.6)$ & $31(2.8)$ & $+1.1(1.5)$ & .46 \\
\hline Between Groups $p$-value ${ }^{a}$ & & & & .77 \\
\hline
\end{tabular}

Note.

* Results shown are based on last observation carried-forward for missing data.

${ }^{a}$ Baseline and 12-Month means are unadjusted. Mean Changes and $p$-values are adjusted by linear regression for baseline score, therapist, age, gender, race, marital status, education, time since RA diagnosis, symptomatic drug use, number of tender joints, number of swollen joints, and sedimentation rate.

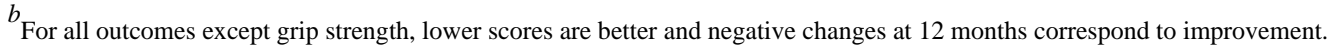

$\mathrm{CBT}=$ Cognitive behavioral therapy; $\mathrm{RR}=$ Relaxation response training; $\mathrm{AE}=$ Arthritis Education; $\mathrm{VAS}=$ visual analog scale . 


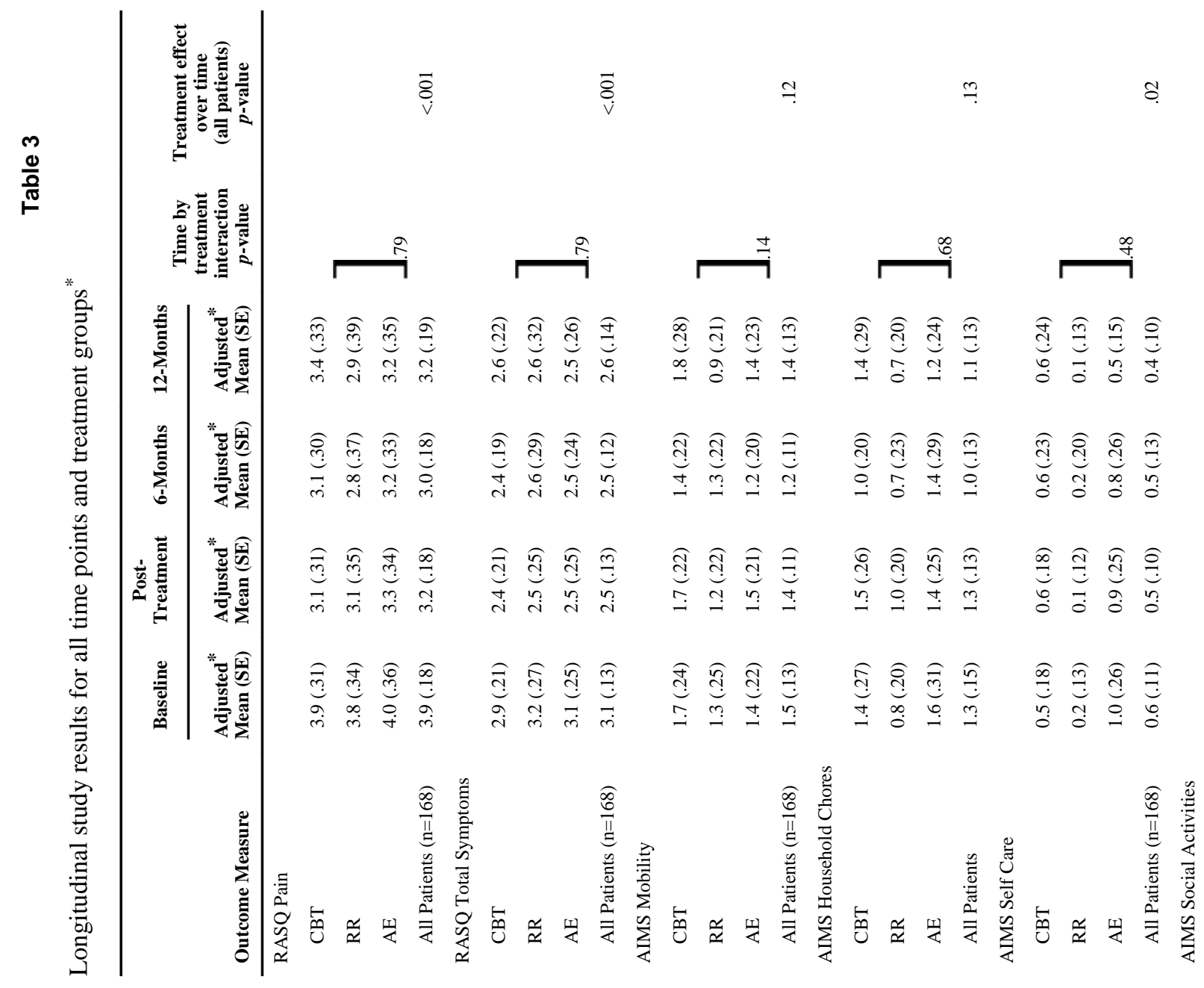




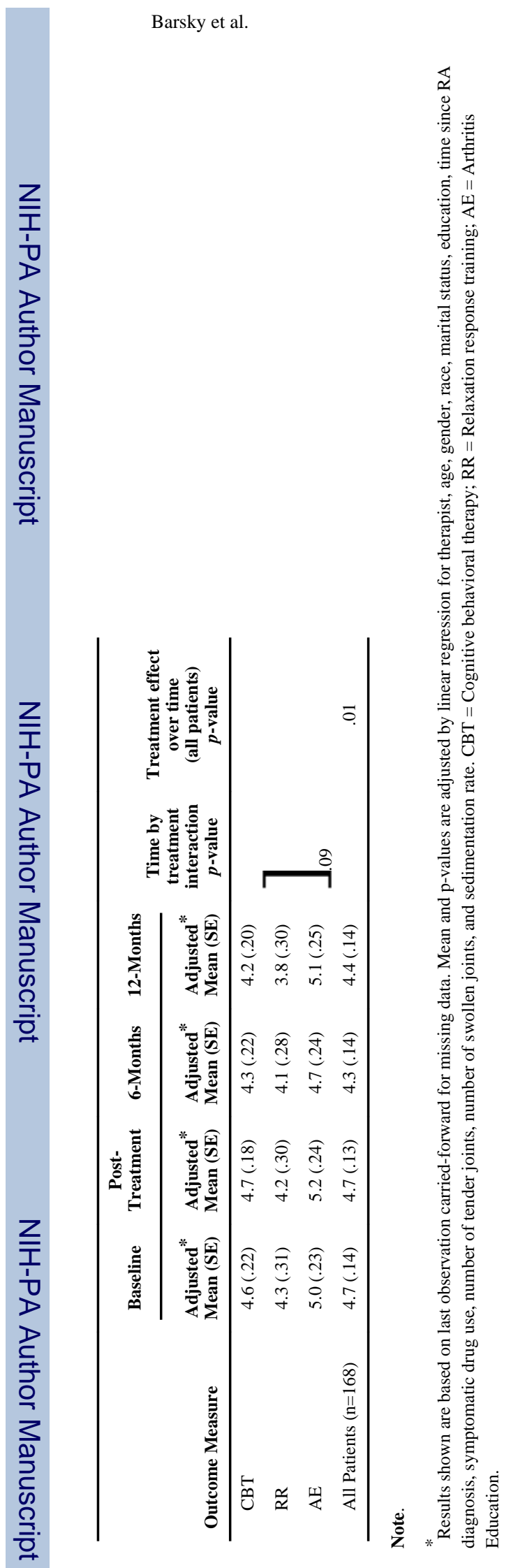

Semin Arthritis Rheum. Author manuscript; available in PMC 2011 December 1. 